\title{
Avaliação externa das aprendizagens dos alunos: reflexos ao nível curricular
}

\section{External evaluation of student learning: reflections at the curricular level}

\author{
Cristina Vicente*, Filipa Seabra** \\ *Universidade Aberta e Agrupamento de Escolas da Sé, **Universidade Aberta e Universidade do Minho
}

\begin{abstract}
Resumo
A autonomia atribuída à escola desencadeia a necessidade de garantir confiança no sistema e regulação das aprendizagens, por parte do Estado. Este artigo procura problematizar de que forma a avaliação externa das aprendizagens dos alunos contribui para o controlo curricular, fundamentando-se numa revisão da literatura. Constata-se que esta avaliação é basilar no processo regulador do Estado, condiciona o currículo e as aprendizagens dos alunos, moldando o ensino de acordo com o que se pretende avaliar. Verifica-se que esta avaliação tem impactos sobre o futuro dos alunos. Analisa-se ainda brevemente o impacto da publicação dos rankings das escolas.

Palavras-chave: avaliação externa, rankings das escolas, ensino secundário
\end{abstract}

\begin{abstract}
The autonomy attributed to schools leads to the State's need to ensure trust in the educational system and regulate learnings. Based on a revision of literature, this article aims to address how the external evaluation of students' learning contributes to curricular control. It is concluded that this evaluation is essential to the State's regulation process, conditions the curriculum and the student's learnings, shaping what is taught according with what is assessed, entailing consequences to the students' futures. The impacts of the publishing of school rankings are briefly analyzed.

Keywords: external evaluation, school rankings, secondary education
\end{abstract}

\section{Introdução}

A avaliação da escola e dos processos e resultados educativos assumem um papel importante na sociedade, por contribuir para a confiabilidade do sistema e a sua regulação, por parte do Estado. A progressiva autonomia dada às escolas dá relevo a esta necessidade, que é concretizada principalmente ao nível da avaliação externa das escolas, praticada pela Inspeção Geral de Educação e Ciência (IGEC), complementada pela avaliação externa das aprendizagens dos alunos, executada pelo Instituto de Avaliação Educativa (IAVE), através das várias análises realizadas aos resultados obtidos, no final de cada ano letivo (Alaíz et al., 2003:18). Neste contexto, Roggero (2002:38) refere que o papel do Estado será o de garantir o controlo do sistema educativo, através da sua avaliação, e avaliação dos seus componentes, uma vez que cada escola é um subsistema do sistema global em que está inserido.
A avaliação externa das aprendizagens dos alunos constitui um instrumento regulador do próprio currículo, na medida em que permite avaliar a forma como este está a ser implementado. O currículo, visto como um plano de ação pedagógica, bem como um conjunto de vivências concretas em contextos de aprendizagem (Aoki, 1993) envolve um conjunto de planificações e decisões a diversos níveis e em diversos contextos (Gaspar \& Roldão, 2005) que cada um dos decisores empreende, com vista ao sucesso dos alunos e à qualidade da escola e das aprendizagens dos alunos. Zabalza (1992:25) entende currículo como "todo o conjunto de ações desenvolvidas pela escola no sentido de criar 'oportunidades de aprendizagem"'. Por outro lado, Figari (1996:94) encara o conceito de currículo do ponto de vista dos decisores e dos alunos. Para os decisores, o currículo designa "o que o professor deve levar a aprender e a maneira como deve proceder". Visto pelo aluno, o currículo define o que ele "tem a oportunidade de aprender", podendo ser também entendido como o percurso educativo que envolve um conjunto de experiências de aprendizagem em que o aluno vai estar envolvido. Do ponto de vista do professor, ele é visto essencialmente como um plano para a aprendizagem, onde se definem os objetivos, os conteúdos e os processos, com vista à aprendizagem dos alunos. Já numa visão mais ampla, ele constitui um conceito central no sistema educativo, uma vez que traduz a operacionalização de todo o processo educativo.

Neste contexto, importa ainda referir o conceito de desenvolvimento curricular. Segundo Roldão (2013:135) o desenvolvimento curricular compreende “a organização de um percurso de ensino e aprendizagem, orientado por finalidades curriculares claras, que seja pensado como o mais adequado à população de alunos em causa, de modo a que efetivamente se apropriem dos saberes e se tornem competentes nas diferentes áreas curriculares”. A noção de desenvolvimento curricular sublinha, assim, o carácter dinâmico do currículo, que não se limita a ser um plano, para ser entendido como processo em ação e recontextualização (Mouraz, Fernandes \& Morgado, 2012) constantes e o papel do professor como decisor curricular (Morgado, 2016).

A avaliação externa exerce uma forma de controlo direto sobre a implementação do currículo e permite 
obter dados acerca do desenvolvimento curricular, informando a tomada de decisões políticas ao nível curricular. Inscreve-se assim no seio de uma lógica de accountability (Seabra, Morgado \& Pacheco, 2012), que a par da autonomia das escolas e do debate intenso e problemático sobre o conceito de 'qualidade' (Leite, Morgado \& Seabra, 2014) tem pautado fortemente o contexto educativo nacional nos anos mais recentes. $\mathrm{Na}$ medida em que a autonomia depende dos resultados de avaliação, faz pender a regulação de um momento $a$ priori (a partir de objetivos e normas) para um momento a posteriori, focado nos resultados (Leite, Morgado \& Seabra, 2014).

Assim, pretende-se compreender o papel da avaliação externa das aprendizagens dos alunos e os seus reflexos ao nível curricular, situando a análise no âmbito do ensino secundário. Procura-se entender de qua forma essa avaliação externa contribui para o controlo curricular e para a avaliação das aprendizagens. Este tema incita também uma reflexão acerca dos rankings de escolas e o seu efeito no contexto social e educativo.

\section{Avaliação e controlo curricular}

A avaliação é um processo complexo e que requer uma reflexão profunda no tocante à sua planificação, na sua operacionalização e também na análise dos resultados obtidos. Concordamos com Morgado (2014: 347) quando defende que o "desenvolvimento de uma cultura de avaliação é sempre uma aspiração positiva, sobretudo se produzir subsídios que contribuam para tornar as pessoas mais conscientes das suas potencialidades e dos seus défices, para estimular o desenvolvimento profissional dos trabalhadores, para contextualizar os processos de trabalho e para melhorar os produtos que oferecem. Contudo, não podemos esquecer que, dada a profusão de significados inerentes ao próprio conceito, a avaliação pode ser [e tem sido] utilizada com fins e intenções diversas, nem sempre condizentes com os propósitos referidos". Importa assim manter uma postura de análise crítica sobre a avaliação externa dos alunos e as formas como é apropriada, sob pena de cairmos em lógicas de performatividade pouco produtivas (Ball, 2003).

Independentemente das ressalvas anteriormente expressas, a avaliação é fundamental para garantir o controlo e a qualidade de qualquer sistema. Em educação este controlo está cada vez mais presente, a par de uma progressiva autonomia das escolas e transferência de poderes de decisão relacionados com a escola e a educação para o domínio local, associada a uma prestação de contas que a escola tem que realizar, através de vários instrumentos, dos quais se destacam: (i) a elaboração de um relatório de autoavaliação; (ii) os resultados obtidos na avaliação externa - de escolas e de resultados dos alunos, reforçando-se na articulação entre estes dois instrumentos a possibilidade de que a avaliação contribua efetivamente para a melhoria da escola (Alaíz et al., 2003). Alaíz et al. (2003:17) citam Afonso (2000:211) para referir que "a avaliação externa das aprendizagens, do currículo ou das escolas está num período de expansão, a que não são alheias as políticas de progressiva autonomia de escolas, como uma nova estratégia concebida para enfrentar o problema de défice da governabilidade". Opinião idêntica é partilhada por Alves (2013:168) ao mencionar que a avaliação externa das aprendizagens permite "criar a convicção de que o sistema de ensino é externamente controlado, e a sua ação é credível e merece confiança". No entanto, para além do controlo que está associado, é fundamental que "se procure potenciar o papel dos exames também ao nível da regulação do ensino e da aprendizagem, bem como da monitorização diacrónica da qualidade do desempenho do sistema educativo" (Sousa, 2014: 112).

Por parte da tutela, este controlo realizado ao nível da educação, tem propósitos específicos e não apenas focados na melhoria das aprendizagens. Do ponto de vista de Fernandes (2014:39) os seus principais objetivos são: “(i) controlar, tendo em vista garantir que os conteúdos previstos no currículo são ensinados e supostamente aprendidos por todos os alunos; (ii) monitorizar, relacionado com a responsabilização e a chamada prestação de contas através dos resultados obtidos pelos alunos; (iii) certificar; e (iv) selecionar, como é, entre nós, o caso no acesso ao ensino superior por parte dos jovens que concluem o ensino secundário".

Constata-se também que os resultados da avaliação externa "constituem uma ferramenta indispensável para assegurar um referencial nacional único na certificação da qualidade da aprendizagem dos alunos, e nessa medida, podem também constituir um instrumento de medida útil na seleção de alunos, nomeadamente no acesso ao ensino superior" (Sousa, 2014:128). O mesmo autor acrescenta ainda que "é essencial usar positivamente o seu potencial efeito de regulação do ensino e da aprendizagem e de monitorização da qualidade do desempenho do sistema educativo" (Sousa, 2014:128).

\section{Avaliação das aprendizagens}

Ao longo de toda a escolarização do indivíduo, a avaliação das aprendizagens é uma das caraterísticas do sistema que tem mais influência direta na vida das pessoas, principalmente na vida dos alunos e das suas famílias. A consequência deste processo, quando se reflete na progressão ou retenção do aluno, permite constatar a complexidade associada e a variedade de fatores que estão envolvidos. No entanto, a temática da avaliação não deve ser a principal questão da educação, mas sim a do processo de ensino-aprendizagem, encarado como o maior desafio que é colocado à escola e que se reflete no sucesso dos alunos. A este respeito, Azevedo (2013:40) refere uma multiplicidade de "sucessos escolares" que importa distinguir: (i) sucesso escolar é aquilo que se mede em exames externos e em provas de avaliação sumativa; (ii) sucesso escolar é a quantidade de crianças e jovens que transitam de ano e de ciclo de estudos; (iii) sucesso escolar é o resultado de um processo de ensino e aprendizagem que proporciona as aprendizagens e a aquisição de saberes que estão consignados; (iv) sucesso escolar é uma dinâmica escolar que implica todos os protagonistas professores, alunos, pais e escola, como um todo - e que 
se ocupa da criação de condições de aprendizagem eficaz por parte de cada um e de todos os alunos. O mesmo autor esclarece ainda que, "enquanto para os dois primeiros o "sucesso" corresponde a uma política que se engalana com quadros e gráficos, os segundos alegram-se mais com a ação quotidiana e humilde que pode fazer com que todos aprendam" (Azevedo, 2013:41). Esta diferença pode ser associada aos conceitos de avaliação externa e avaliação interna, respetivamente. No entanto, a avaliação interna, por depender dos critérios de avaliação aprovados em cada escola, e da sua aplicação por parte de cada professor, está longe de ser uma avaliação com garantias de imparcialidade e muitas vezes de credibilidade, quando se observam enormes disparidades entre as classificações interna e externa obtidas pelos alunos.

A este respeito, Fernandes (2014:44) refere que "na verdade, uma das razões que justifica a utilização das avaliações externas é o facto de as avaliações internas não serem suficientemente credíveis (e.g., válidas, fiáveis) para poderem ser consideradas para efeitos de responsabilização e de prestação de contas, exigências dificilmente contornáveis nas sociedades atuais". Daí que tenha que haver uma articulação/ complementaridade entre a avaliação interna e a avaliação externa, para que seja possível ultrapassar os pontos críticos de cada uma delas e seja possível avaliar os alunos e o sistema educativo de uma forma equilibrada, para que os resultados obtidos possam contribuir para a melhoria efetiva do sistema educativo.

Numa perspetiva complementar, Roldão (2013:135) refere, a propósito da importância da avaliação, que esta não serve apenas para identificar os problemas e os insucessos, serve também para desmontar criticamente as situações bem-sucedidas e assim "identificar, situar e analisar os fatores de sucesso e adequação, no sentido de os rentabilizar em situações futuras".

Por outro lado, Alves (2013:169) defende que uma correta avaliação das aprendizagens passa pela "utilização de uma diversidade de fortes de informação, o uso de diversos métodos, a coleta de informações ao longo do tempo, a ponderação da valia e do mérito das aprendizagens", trata-se segundo o autor, de triangular dados para produzir uma classificação mais justa.

Esta opinião vai ao encontro do parecer de Zabalza (1992:239), que realça o principal destinatário da avaliação - o aluno, ao referir que "podemos fazer uma avaliação muito correta do ponto de vista técnico mas, se dela derivarem consequências negativas, de nada terá valido". Importa assim tomar em linha de conta a avaliação externa não por si só, mas como um dos elementos de um processo de avaliação mais complexo e abrangente.

\section{Avaliação externa}

A ideia de melhoria constante do sistema de ensino está diretamente relacionada com a implementação de uma avaliação externa das aprendizagens (incluindo exames e provas de aferição). Relativamente à utilidade dos exames, Alves (2013:156) assume uma posição crítica e refere "que existem, não para averiguar o que o aluno aprendeu de significativo e relevante para a sua vida presente e futura, mas para determinar o que ele não sabe". O mesmo autor expõe a rutura que muitas vezes existe entre o que é ensinado, o que é aprendido e o que é examinado, alertando que a preocupação do IAVE é produzir exames inovadores "parecendo assumir isso como fator meritório, mas esquecendo que a prova não pode deixar de ter como referência dois contextos específicos: o programa da disciplina e as práticas de ensino" (Alves, 2013:160). Este autor questiona mesmo a validade dos exames ao referir que "não medem o que é suposto medir. Avaliam o que não foi ensinado". No entanto reconhece algumas vantagens na sua realização quando são utilizados como "um dos instrumentos de avaliação", servindo ainda como "fator de sistematização de conhecimentos e de alguma igualização face a uma grande desigualdade nos sistemas produtores das avaliações internas" (Alves, 2013:168).

Neste contexto, Alaíz et al. (2003:18) referem que, para além das funções de controlo associadas à realização da avaliação externa, existem outras muito importantes nas que se incluem a possibilidade de refletir sobre os resultados alcançados e posterior definição de prioridades dos objetivos de melhoria, "potenciando a função formativa da avaliação".

Para além do seu objetivo principal, que é a melhoria da qualidade de ensino e da qualidade das aprendizagens, Fernandes (2014:41) refere que "as avaliações externas, nacionais e internacionais, constituem símbolos e medidas irrefutáveis da qualidade dos sistemas educativos e, concomitantemente, da qualidade dos seus professores, das suas escolas e dos seus currículos. Porém, não há, [...] qualquer evidência científica que comprove essa ideia, essa crença".

Outra implicação direta do processo de avaliação externa das aprendizagens, está associada ao peso que a avaliação externa tem na classificação final de cada disciplina. Neste aspeto, partilha-se a opinião de Alves (2013:169) ao considerar que no ensino secundário, a conjugação da avaliação interna com a avaliação externa tem algum equilíbrio, uma vez que a proporção se apresenta com $70 \%$ e $30 \%$, respetivamente. No entanto, a peso de $50 \%$ como ponderação na nota de acesso ao ensino superior é considerada excessiva, tendo em conta as considerações já realizadas acerca das características da avaliação externa. Assim, constata-se que, apesar se apresentarem como instrumentos de equidade e justiça, os exames são instrumentos "ao serviço da seleção social, da consagração das desigualdades sociais e da imputação pessoal do insucesso" (Alves, 2013:163).

\section{Os rankings de escolas}

Os rankings das escolas são uma consequência da divulgação pública dos resultados da avaliação externa das aprendizagens. Assumida por muitos como a "polémica dos rankings", Sousa (2014:150) duvida se os rankings das escolas dão a perceção da real qualidade das escolas. Relativamente ao foco que é dado pela comunicação social aos resultados da avaliação externa, Azevedo (2013:41) questiona se a publicitação alargada de gráficos e estatísticas tem implicações diretas na 
motivação dos alunos e dos professores para aprender e ensinar melhor, questiona também se o empenho real dos alunos para alcançar os resultados pretendidos, é aumentado, ou mesmo se estes passam a conhecer melhor os objetivos de aprendizagem. O mesmo autor expõe ainda o favorecimento meramente exibicionista dos estabelecimentos de ensino, em desfavor dos objetivos ligados ao domínio do saber. Esta opinião é partilhada por Alaíz et al. (2003:17) ao constatar que as escolas do setor privado usam os resultados da avaliação externa como um "importante trunfo a exibir perante os seus potenciais clientes na tentativa de conquistar maiores fatias de mercado". É por isso necessário refletir sobre o interesse e a potencial mais-valia do contínuo e repetido uso mediático da informação produzida, em torno da aplicação dos exames (Sousa, 2014:121).

A utilização dos resultados das avaliações externas para o estabelecimento de rankings das escolas é, segundo Sousa (2014:125) "uma situação que, embora tendencialmente se esteja a corrigir, ainda introduz uma profunda distorção na forma como se processa a apropriação social da qualidade do desempenho das organizações escolares". Neste sentido, é necessário criar um sistema de referenciação claro, pelo avaliador, neste caso o Ministério da Educação e Ciência, que permita a aplicação de um método que especifique uma forma de "estabelecer e objetivar as regras de uma procura de informações utilizáveis pelos atores do dispositivo avaliado, assim como de clarificar os referentes em relação aos quais essas informações poderão ser lidas" (Figari, 1996:178).

Assim, relativamente à discussão pública dos resultados decorrentes da avaliação externa das aprendizagens e a sua relação com os rankings de escolas, partilha-se a opinião de Sousa (2014:115), ao reconhecer que "o problema não reside nos exames enquanto instrumentos de medida do sucesso educativo, mas sim na forma como são vivenciados por quem os realiza e por quem divulga e por quem lê e usa os respetivos resultados".

\section{Implicações da avaliação externa das aprendizagens dos alunos no desenvolvimento curricular}

As consequências que a avaliação externa das aprendizagens pode provocar, ao nível do desenvolvimento curricular, podem ser analisadas de acordo com cada um dos três níveis de decisão curricular: (i) político/administrativo - no âmbito da administração central; (ii) de gestão - no âmbito da escola e da administração regional; (i) de realização no âmbito da sala de aula (Pacheco, 2005:54). Nos dois primeiros contextos os resultados obtidos permitem informar acerca da implementação do currículo (gestão) e fundamentam a tomada de decisões a nível macro (politico/administrativo), onde se tomam muitas das decisões acerca das questões curriculares. Neste patamar, os resultados dos exames e as estatísticas produzidos, serão o suporte para a tomada de decisões relativas aos seguintes aspetos: (i) aferição dos conhecimentos dos alunos a nível nacional; (ii) adequação dos currículos; (iii) adequação dos programas das disciplinas; (iv) regulação das práticas pedagógicas e das didáticas das disciplinas; (v) adequação aos vários tipos de alunos e escolas; (vi) avaliação das escolas (Sousa, 2014:136). A avaliação externa contribui para intervenções diretas e indiretas, sobre o currículo, na medida em que "tem também como grande objetivo fornecer informação para que os decisores políticos possam elaborar ou ajustar as medidas de política educativa, necessárias para uma melhoria do sistema de ensino" (Santos, 2014:143). O mesmo autor acrescenta que os resultados dos exames permitem também avaliar a qualidade do trabalho das escolas e dos professores e "podem ser a base de trabalho para analisar esses resultados, determinar as causas e empreender programas de melhoria".

Por outro lado, ao nível meso, o olhar das escolas sobre os dados da avaliação externa, tal como refere Santos (2014:137), tem como objetivo "um verdadeiro e efetivo processo de autoavaliação, pelo que deve ter em conta três níveis principais de análise, nomeadamente: (i) análise de nível macro - comparação com os dados estatísticos nacionais; (ii) análise de nível intermédio comparação com os dados estatísticos regionais (NUTS III e Concelho); (iii) análise de nível local - análise fina dos resultados obtidos pelos alunos da escola".

Ao nível micro, as influências dos resultados, do ponto de vista do professor e suas consequências práticas dentro da sala de aula, estão associadas à última fase do desenvolvimento curricular. Gaspar e Roldão (2005) caraterizam cada uma das três fases da seguinte forma: (i) conceção/elaboração - em que se procede ao estabelecimento de objetivos e conteúdos e a sua orientação para competências a desenvolver; (ii) operacionalização - onde o professor define a estratégia de ensino para que os seus alunos alcancem o objetivo/conteúdo pretendido e o coloca em ação; (iii) avaliação - onde se procede à análise dos resultados de avaliação obtidos na fase de operacionalização e faz um questionamento/reflexão acerca do sucesso das estratégias/instrumentos e atividades realizadas com vista aos objetivos definidos. Assim, para os professores, a análise dos resultados pode contribuir para ajudar o professor "a rever os seus métodos e melhorar as suas formas de ensinar" (Alves, 2013:168).

Pelo exposto, constata-se que a reflexão sobre todas as informações produzidas pela análise dos resultados da avaliação externa, faz com que as implicações apontadas possam contribuir para melhorar a qualidade do sistema de ensino, aos níveis, macro, mas também meso e micro, atendendo à autonomia das escolas e ao papel dos professores como decisores curriculares, por se estar na posse de "informação credível que nos permita melhorar o currículo, a avaliação e as didáticas, tendo em consideração todas as especificidades e diversidades que caracterizam o nosso sistema educativo" (Sousa, 2014:151).

\section{Conclusão}

A avaliação externa das aprendizagens dos alunos é um instrumento de avaliação questionado, do ponto de vista do seu contributo para a melhoria das 
aprendizagens dos alunos, embora muito utilizado ao nível do controlo curricular e que, a par de outras formas de avaliação assume relevância e significado. Quando se questiona o que se pretende fazer com a avaliação externa, constata-se que esta serve para monitorizar a qualidade da educação e para definir ou reformular políticas educativas que permitam aumentar o sucesso educativo, tendo em conta os padrões de excelência que se desejam atingir. No entanto, “é preciso pensar que as avaliações externas não podem, por si sós, resolver os problemas. Têm que ser delineadas de forma mais integrada e articulada com outros processos de avaliação, internos e externos, e apoiadas em políticas ativas materializadas em programas focados nas aprendizagens dos alunos" (Fernandes, 2014:46). A trilogia que pode ser criada entre a avaliação externa, o currículo e as aprendizagens dos alunos, pode nem sempre coincidir. Este facto é assinalado por Alves (2013:165), ao alertar que os exames "sobredeterminam e empobrecem o currículo, uma vez que o ensino e a aprendizagem são determinados não pelo currículo e pelo programa, mas pelo exame", realidade esta que assume especial relevo no âmbito do ensino secundário e do acesso ao ensino superior.

Pela sua repercussão ao nível mediático e social, constata-se que a publicação dos resultados da avaliação externa serve para prestar contas à sociedade e mostrar a eficiência da função do Estado, no que se refere à educação. Neste caso, observa-se frequentemente que a sociedade está mais interessada no sucesso escolar, publicitado pelos media, do que com o sucesso real de cada aluno, sem fazer um esforço em compreender os contextos associados à mediatização dos resultados estatísticos (Azevedo, 2013:42). Do ponto de vista educativo, todos estes sistemas de avaliação e reflexão sobre os resultados obtidos, permitem sustentar o processo de decisão das medidas a implementar, por forma a garantir a melhoria dos resultados, com base na produção de informação útil, clara e contextualizada, avalizando que o sistema educativo continua a garantir a sua função principal: educar os alunos. Estes potenciais efeitos reguladores e formativos não obstam a que se mantenha um olhar crítico sobre a avaliação, questionando o seu processo, os seus resultados e o uso que deles é feito de modo a procurar orientá-los para a melhoria, em detrimento de pressões para a performatividade dos docentes e das escolas, que limitam a sua capacidade de se assumirem como decisores curriculares de excelência.

\section{Referências bibliográficas}

Alaíz, V., Góis, E. \& Gonçalves, C. (2003). Autoavaliação de escolas - Pensar e Praticar. Porto: Edições Asa.

Alves, J. (2013). Exames: Mitos e realidades. In J. Machado \& J. Matias Alves (Orgs). Melhorar a Escola: Sucesso escolar, disciplina, motivação, direção de escolas e políticas educativas (pp.155169). Porto: Católica Porto.
Aoki, T. T. (1993). Legitimating lived curriculum: towards a curricular landscape of multiplicity. Journal of Curriculum and Supervision, 8(3), 255-268.

Azevedo, J. (2013). Como se tece o (in)sucesso escolar: o papel crucial dos professores. In J. Machado \& J. Matias Alves (Orgs). Melhorar a Escola: Sucesso escolar, disciplina, motivação, direção de escolas $e$ políticas educativas (pp. 39-54). Porto: Católica Porto.

Ball, S. (2003). The teachers' soul and the terrors of performativity. Journal of Educational Policy, 18(2), 215-228.

Fernandes, D. (2014). Introdução ao seminário. In M. Miguéns, (Coord). Avaliação externa e qualidade das aprendizagens. Seminários e colóquios. Lisboa: CNE.

Figari, G. (1996). Avaliar, que Referencial?. Porto: Porto Editora

Gaspar, M., \& Roldão, M. (2005). Elementos do Desenvolvimento Curricular. Lisboa: Universidade Aberta.

Leite, C., Morgado, J. C., \& Seabra, F. (2014). External School Evaluation in Portugal - a glance at the impacts on curricular and pedagogical practices. European Journal of Curriculum Studies, 1(1), 33-43.

Morgado, J. C. (2014). Avaliação e qualidade do desenvolvimento profissional docente: que relação? Avaliação, 19(2), 345-361.

Morgado, J. C. (2016). O professor como decisor curricular: de ortodoxo a cosmopolita. Revista Tempos e Espaços em Educação, 9(18), 55-64.

Mouraz, A., Fernandes, P., \& Morgado, J. C. (2012). Contextualisation Curriculaire; des discours aux pratiques. La Recherche en Education, 7, 31-44.

Pacheco, J. A. (2005). Estudos Curriculares: Para a compreensão crítica da educação. Porto: Porto Editora.

Roggero, P. (2002). Avaliação dos sistemas educativos nos países da União Europeia: de uma necessidade problemática a uma prática complexa desejável. Eccos Revista Científica, 4(2), 31-46.

Roldão, M. C. (2013). Desenvolvimento do currículo e melhoria de processos e resultados. In. J. Machado \& J. Matias Alves (Orgs). Melhorar a Escola: Sucesso escolar, disciplina, motivação, direção de escolas $e$ políticas educativas (pp. 131-140). Porto: Católica Porto.

Santos, L. (2014).Um olhar sobre os dados da avaliação externa da aprendizagem. In. M. Miguéns (Coord), Avaliação externa e qualidade das aprendizagens. Seminários e colóquios. Lisboa: CNE.

Seabra, F., Morgado, J. C., \& Pacheco, J. A. (2012). Policies of Accountability in Portugal. International Journal of Curriculum and Instructional Studies, 2(4), 41-51.

Sousa, H. (2014). Qualidades, defeitos e limitações do sistema de avaliação externa em Portugal. In. M. Miguéns (Coord), Avaliação externa e qualidade das aprendizagens. Seminários e colóquios. Lisboa: CNE.

Zabalza, M. (1992). Planificação e desenvolvimento curricular na escola. Rio Tinto: Edições Asa. 